\title{
Dificuldades nos processos de ensino e de aprendizagem de Cálculo Diferencial e Integral
}

\section{Difficulties in the teaching and learning process of Differential and Integral Calculus}

\author{
Josué Antunes de Macêdo
}

Isabela Cristina Soares Gregor

\begin{abstract}
Resumo: A disciplina de Cálculo Diferencial e Integral (CDI) é ministrada em seis dos nove cursos superiores do Instituto Federal de Educação Ciência e Tecnologia do Norte de Minas Gerais (IFNMG), campus Januária, e possui um alto índice de reprovação comparado com outras disciplinas. Este artigo mostra os resultados de uma pesquisa em que se buscou encontrar respostas para as principais dificuldades enfrentadas por alunos e professores da disciplina de $\mathrm{CDI}$, em relação aos processos de ensino e de aprendizagem. Para a obtenção dos dados foram aplicados questionários aos alunos da disciplina e aos professores que ministram ou já ministraram tal disciplina no campus, bem como monitorias para um grupo de alunos. Os resultados mostram a realidade no ensino e na aprendizagem de CDI no campus Januária e abre as portas para discussões acerca desta problemática que abrange não só o IFNMG, como também outras instituições de Ensino Superior no Brasil.
\end{abstract}

Palavras-chave: Cálculo Diferencial e Integral. Dificuldades de aprendizagem. Ensino Superior.

Abstract: The Differential and Integral Calculus (DIC) course is taught in six of the nine undergraduate courses of the Federal Institute of Education, Science and Technology of the North of Minas Gerais (IFNMG), campus Januária and has a high failure rate compared to other subjects. This paper shows the results of a research which sought to find answers to the main difficulties faced by students and teachers of the DIC course, in relation to the teaching and learning process. In order to obtain the data, questionnaires were applied to the students of the course and to the teachers who teach or have already taught this course on the Campus, as well as monitoring for a group of students. The results show the reality of DIC teaching and learning at Campus Januária and opens the door for discussions about this issue that covers not only the IFNMG, but also other higher education institutions in Brazil.

Keywords: Differential and Integral Calculus. Learning Difficulties. Higher Education.

\section{Introdução}

O ensino de Cálculo Diferencial e Integral (CDI) está cada vez

Josué Antunes de Macêdo Doutor em Ensino de Ciências e Matemática. Professor do Instituto Federal de Educação, Ciência e Tecnologia do Norte de Minas Gerais (IFNMG), campus Januária. Professor Colaborador do Programa de Pós-Graduação em Educação da Universidade Estadual de Montes Claros (Unimontes). Minas Gerais,

$$
\text { Brasil. }
$$

(iD) orcid.org/0000-0001-7737-7509

\josueama@gmail.com

Isabela Cristina Soares Gregor Licenciada em Matemática pelo Instituto Federal de Educação, Ciência e Tecnologia do Norte de Minas Gerais (IFNMG).

Professora da Secretaria de Estado da Educação de Minas Gerais (SEE-MG). São Paulo, Brasil.

(iD) orcid.org/0000-0001-5780-2408 $\bowtie$ isabellagregor@hotmail.com

Recebido em 20/01/2020 Aceito em 02/03/2020 Publicado em 04/04/2020 mais presente nos cursos superiores, e mostra a importância da disciplina para o desenvolvimento do conhecimento científico. Porém, o desempenho insatisfatório dos alunos nessa disciplina tem 
preocupado pesquisadores de todo o mundo, com níveis altíssimos de reprovação e desistências em cursos de Licenciaturas e Engenharias, conforme salienta Silva (2009).

No Instituto Federal de Educação, Ciência e Tecnologia do Norte de Minas Gerais (IFNMG), campus Januária, a disciplina de Cálculo Diferencial e Integral é ministrada em seis dos nove cursos superiores, sendo eles bacharelados em Agronomia, Engenharia Agrícola e Ambiental, Sistemas de Informação e em Engenharia Civil, e Licenciaturas em Física e em Matemática. A disciplina não é ministrada somente nos cursos superiores de Administração, Licenciatura em Ciências Biológicas e Tecnologia em Análise e Desenvolvimento de Sistemas.

Este estudo torna-se relevante, uma vez que investigou as possíveis causas de evasão e desistências nas disciplinas de CDI e as principais dificuldades apresentadas pelos alunos do campus Januária, visando encontrar possíveis contribuições para mudar a situação dos dados atuais.

Sendo assim, por meio do conhecimento das principais dificuldades dos alunos e das possíveis causas das reprovações e desistências nas disciplinas de CDI, será possível um planejamento adequado para melhorar o ensino e o aprendizado da disciplina e contribuir para que a instituição possa se reorganizar diante do problema, dos resultados obtidos e das possíveis soluções apresentadas pela pesquisa.

Uma das alternativas verificada durante a pesquisa foi o uso de softwares matemáticos, tais como o GeoGebra, para um estudo mais detalhado e compreensivo dos conceitos e teoremas do Cálculo e, também, monitorias com foco em conceitos fundamentais da Matemática para 0 aprendizado do conteúdo.

Este artigo é composto por sete seções, incluindo esta introdução e as considerações finais ${ }^{1}$. A seção dois aborda o uso de testes diagnósticos no ensino.

Na seção três são abordados os temas que dão suporte ao estudo realizado, na qual foi feita uma abordagem bibliográfica sobre as dificuldades apresentadas no ensino e na aprendizagem de CDI, com foco em pesquisas recentes que abordam a questão das dificuldades apresentadas pelos alunos dos períodos iniciais dos cursos superiores que possuem a disciplina

\footnotetext{
1 Versões preliminares da pesquisa relatada neste artigo foram publicadas nos anais do IV Seminário Nacional de Educação Profissional e Tecnológica (GEGOR et al., 2014); anais do V Encontro Nacional das Licenciaturas (GREGOR, MACÊDO e AMORIM, 2014); e nos anais do $4^{\circ}$ Simpósio Internacional de Pesquisa em Educação Matemática (GREGOR e MACÊDO, 2015).
} 
de CDI I.

Já a seção quatro apresenta uma discussão a respeito do uso das Tecnologias Digitais (TD) na Educação Matemática, com foco no Ensino Superior de CDI.

Na seção cinco, faz-se a apresentação da metodologia utilizada na coleta dos dados, descrevendo as características dos componentes de cada turma avaliada e, também, na forma como os dados foram contabilizados para realização da análise.

A análise dos dados obtidos na pesquisa é discutida na seção seis, na qual, por meio da análise dos erros cometidos pelos alunos e das opiniões apresentadas no teste, são analisados os principais erros e suas causas. Também são discutidas as respostas dos professores e realizada uma análise do índice de aprovação e reprovação na disciplina de CDI no campus Januária.

A conclusão deste trabalho é apresentada na sétima seção, em que se buscou, a partir da análise dos dados, discutir e encontrar respostas sobre as dificuldades trazidas pelos alunos até o Ensino Superior e quais as possíveis causas.

\section{Uso de testes diagnósticos no ensino}

Espera-se que os estudantes, ao ingressar no Ensino Superior, possuam os conhecimentos adquiridos no Ensino Básico, que são a base para a aprendizagem dos novos conteúdos. No entanto, na maioria das vezes isso não ocorre. Para que a aprendizagem seja de fato significativa, faz-se necessário que o professor conheça o quanto seus alunos sabem, ou seja, o nível de conhecimento prévio em determinada disciplina.

Para a disciplina de Cálculo Diferencial e Integral este fato torna-se importante, pois para trabalhar os conteúdos presentes nas ementas do Cálculo é necessário que os alunos tenham domínio dos conteúdos básicos de Matemática para que consigam prosseguir em seus estudos.

Uma alternativa encontrada e utilizada no Ensino Superior é a aplicação de testes diagnósticos nas turmas de CDI antes de dar início ao conteúdo programático. Isso permite ao professor avaliar o conhecimento dos alunos nos conteúdos básicos de Matemática. A partir dos resultados, torna-se possível planejar adequadamente os conteúdos, buscando assim alternativas que possibilitem aos estudantes meios mais eficazes de aprendizagem. 
De acordo com uma pesquisa realizada na Pontifícia Universidades Católica do Rio Grande do Sul, Bressan et al. (2009) relatam o uso de testes de sondagem aplicados no início de cada semestre letivo nas turmas de CDI I:

Nesta perspectiva, a cada início de semestre letivo é aplicado um teste de sondagem envolvendo conteúdos de Matemática do Ensino Fundamental e Médio. A partir daí, são elaborados e disponibilizados materiais sobre tais conteúdos e sobre os específicos do Cálculo, para estudos complementares dos alunos. (p. 1173)

O teste de sondagem, ou diagnóstico, mostra-se excelente ferramenta no campo do Cálculo, pois realiza uma sondagem do conhecimento dos alunos e permite uma intervenção que poderá trazer resultados satisfatórios, como uma considerável melhoria nos processos de ensino e de aprendizagem dos assuntos que são necessários para a aprendizagem do Cálculo.

Nota-se que esta ferramenta pode auxiliar de maneira relevante alunos e, também, professores, pois permite a análise das dificuldades dos alunos e posterior intervenção por parte dos professores, tornando assim possível uma melhor aprendizagem de Cálculo Diferencial e Integral.

\section{Dificuldades no ensino e na aprendizagem do Cálculo Diferencial e Integral}

A disciplina de Cálculo Diferencial e Integral, assim como outras disciplinas da área de Ciências Exatas, exige dedicação, responsabilidade e organização por parte de alunos e professores. Porém, algumas pesquisas, como as realizadas por Rezende (2003), Cavassotto e Portanova (2008), Wrobel, Zeferino e Carneiro (2013) e Santos e Carneiro (2013), apontam altos índices de reprovações e desistências nesta disciplina. Onde está o problema? Quem são os culpados: alunos ou professores?

A disciplina de CDI é uma parte importante do conhecimento, que têm inúmeras aplicações em diversas áreas que compõe o conhecimento científico humano como a Engenharia, a Física, a Astronomia, a Matemática, a Mecânica, ente outras, auxiliando, assim, um constante estudo quanto à sua aplicabilidade no campo científico.

A principal tarefa do professor é realizar uma transposição didática eficaz, ou seja, transformar o conhecimento científico em conhecimento escolar, passível de ser compreendido pelos alunos, como defende Freire (2011), em seu livro Pedagogia da Autonomia. No entanto, esta tarefa está se tornando cada vez mais difícil de ser cumprida. 
Os professores enfrentam vários desafios dentro e fora da sala de aula. Dentre os mais comuns, pode-se citar a falta de interesse por parte dos alunos e a defasagem escolar, as dificuldades em realizar novas atividades no local de trabalho e 0 uso das tecnologias digitais nas aulas, que também dificultam uma melhor aprendizagem. Nas disciplinas de CDI o cenário é 0 mesmo, se não for pior.

A Matemática é vista, e muitas vezes repassada, como sendo uma disciplina de alto nível de dificuldade, em que poucos conseguem aprendê-la, como afirma Vieira (2013): "[...] esta disciplina continua considerada a vilã entre todas as áreas do conhecimento" (p. 25). Este fato torna seu ensino e aprendizado muito mais difíceis, pois cria uma ideia errônea do que é a Matemática, muitas vezes sendo ministrada aos alunos como algo pronto e acabado.

Ao ingressar no Ensino Superior, os alunos se deparam com uma nova realidade que se refere à busca pelo conhecimento, uma nova fase na qual terão de estudar fora da sala de aula e de modo independentes. No entanto, ainda não há maturidade suficiente por parte dos alunos que dificulta sua adaptação à nova fase e sua aprendizagem em disciplinas que exigem muita dedicação e organização, como é o caso do CDI.

De acordo com Godoy e Faria (2012), as reprovações em disciplinas de Cálculo têm se tornado uma rotina e considerado normal por alunos e professores, principalmente nos períodos iniciais dos cursos de Engenharia, que em sua maioria é ministrada no primeiro período. Para Gomes (2012), isso deve-se ao fato de que "ministrada no início do curso, [Cálculo l] passa a ser o primeiro contato, para o aluno, com uma Matemática 'diferente' daquela que trabalhava no Ensino Médio" (p. 1).

O Ensino Básico público está precário, em sua maioria formando alunos que mal sabem as operações matemáticas fundamentais, e este fato reflete no Ensino Superior, no qual as maiores dificuldades dos alunos estão no conhecimento científico básico, necessário para um bom rendimento em disciplinas matemáticas, como é o caso do Cálculo Diferencial e Integral.

Conforme a pesquisa de Santos e Carneiro (2013), realizada no Instituto Federal de Educação Ciência e Tecnologia do Ceará (IFCE), campus Maracanaú,

segundo os professores, o conhecimento matemático é, por natureza, encadeado e cumulativo, de modo que o desconhecimento de conceitos elementares pode impedir ou até mesmo dificultar a compreensão dos conceitos subsequentes. Portanto, ao problema da falta de conhecimento básico de Matemática, deve-se dar uma importância maior, haja visto ser um pré-requisito para a disciplina em questão. (p. 7) 
Os alunos chegam ao Ensino Superior com um conhecimento superficial dos conteúdos matemáticos, o que dificulta a compreensão e absorção dos teoremas, conceitos e cálculos desta disciplina. Portanto, faz-se necessário dar mais atenção às dificuldades dos alunos na disciplina de Cálculo Diferencial e Integral e buscar meios de resolver esta questão.

É necessário rever os meios didáticos e seus valores no ensino de Matemática, pois ela está presente em todas as outras áreas e é responsável por grande parte do desenvolvimento lógico do conhecimento humano.

Segundo Nasser (2007), pesquisas apontam que as principais dificuldades dos alunos na disciplina de CDI estão na compreensão das noções de função, limites e derivadas, no domínio do Teorema Fundamental do Cálculo ou na forma como os alunos estudam, sendo que este último item é um dos pontos discutidos neste trabalho.

É comum ouvir dos alunos iniciantes comentários a respeito da disciplina de CDI, enfatizando a novidade que é lidar com o Cálculo Diferencial e Integral. A realidade é que a grande maioria dos alunos advindos de escolas públicas nunca teve contato com tal disciplina ou algo parecido.

Guedin (2004) salienta que por ser dinâmico e tratar principalmente de taxa de variação, o Cálculo Diferencial e Integral é muito diferente de outros temas estudados pelos alunos que ingressam nos cursos superiores, logo é natural eles terem dificuldades na compreensão dos teoremas, conceitos e até mesmo cálculos abordados na disciplina.

Segundo Rodrigues et al. (2011), muitos estudos relacionados ao ensino e à aprendizagem de CDI apontam para problemas que evoluem gradativamente, que acumulam no decorrer de todo o Ensino Básico, culminando no Ensino Superior.

Pesquisas relacionadas à aprendizagem de CDI foram realizadas no Brasil com foco nas dificuldades na disciplina de Cálculo Diferencial e Integral I, dentre elas podemos citar Bressan et al. (2009), na Pontifícia Universidade Católica do Rio Grande do Sul (PUCRS); Lacaz, Carvalho e Fernandes (2007), na Faculdade de Engenharia de Guaratinguetá (FEG/UNESP); e Santos e Carneiro (2013), no Instituto Federal de Educação Ciência e Tecnologia do Ceará (IFCE).

Os estudos realizados em diversas universidades vêm contribuindo cada vez mais na melhoria do ensino e da aprendizagem de CDI, pois utilizam como instrumento de pesquisa os acadêmicos da própria instituição, buscando respostas e intervenções adequadas à realidade do 
Ensino Superior, como relata a pesquisa apresentada neste trabalho.

Portanto, para compreender as dificuldades dos alunos na disciplina de CDI, faz-se necessária uma avaliação dos conhecimentos matemáticos que estes possuem até sua chegada ao Ensino Superior e, a partir desta, buscar intervenções adequadas e dinâmicas.

\section{O uso das tecnologias digitais no ensino de Cálculo Diferencial e Integral}

É inegável o desenvolvimento tecnológico apresentado pela sociedade atual. $\mathrm{O}$ uso das tecnologias digitais (TD) tornou-se prático e acessivel de maneira dominante em todas as classes sociais, fazendo com que as informações sejam transmitidas em altíssima velocidade. $\mathrm{Na}$ Educação, o uso das tecnologias digitais vem ganhando espaço. Em especial as TD mostrou ser um instrumento prático e eficiente no ensino de Matemática, principalmente no estudo das funções e gráficos, além das figuras espaciais.

Atualmente existem diversos softwares educacionais desenvolvidos para a área da Educação Matemática, alguns são livres, outros gratuitos ou proprietários, todos com o objetivo de torná-la mais dinâmica e clara, no intuito de melhorar o ensino e a aprendizagem dos conteúdos matemáticos. Dentre eles, pode-se citar Winplot, GeoGebra, Régua e Compasso (Compass and Ruler - C.a.R.), Graphmatica, MATLAB, Mathematica, entre outros, os quais auxiliam alunos e professores na aprendizagem e no ensino de diversos conteúdos matemáticos.

No segundo semestre de 2012 foi desenvolvido para os acadêmicos dos cursos de Licenciatura em Matemática e Física do IFNMG, campus Januária, um curso de extensão intitulado Funções transcendentes com o uso dos softwares Winplot e GeoG3ebra, com o objetivo de avaliar a viabilidade do uso dos softwares matemáticos na melhoria do ensino e do aprendizado da Matemática, além de buscar resultados relevantes da pesquisa para a formação acadêmica.

O foco do minicurso foi o estudo das funções transcendentais, conteúdo ainda pouco explorado nos cursos do IFNMG, campus Januária. O minicurso realizado foi importante para avaliar os benefícios tecnológicos na formação inicial de professores (SANTOS e MACÊDO, 2013; 2015; MACÊDO e SANTOS, 2019). De acordo com a conclusão do trabalho realizado por Santos e Macêdo (2013), 
abordadas por parte dos acadêmicos, desse modo, ficou claro aos cursistas que em determinados momentos nas aulas de Matemática, é viável a utilização de softwares ao invés das mídias lápis e papel. (p.13)

Pode-se observar que o minicurso proporcionou aos cursistas um entendimento mais claro quanto ao comportamento das funções transcendentes por meio dos softwares, e quanto a viabilidades da utilização destes para o ensino de determinados conteúdos matemáticos.

A tecnologia é uma excelente ferramenta, e se usada adequadamente, especialmente no Ensino Superior, pode auxiliar os alunos no estudo do Cálculo Diferencial e Integral, nos quais os softwares matemáticos colaboram para a compreensão de conteúdos e na resolução de problemas através de ferramentas gráficas.

\section{Metodologia}

Para a obtenção dos dados analisados neste artigo foi elaborado um questionário em duas partes: a primeira parte composta por questões que abordam conteúdos básicos de Matemática ministrados no Ensino Médio, e a segunda parte composta por questões relacionadas à disciplina de Cálculo Diferencial e Integral. Esse questionário permitiu analisar a situação dos alunos no início dos estudos do CDI. Para efeito de análise, a primeira parte do questionário foi denominada de Q1 e a segunda parte, de Q2.

Este questionário foi aplicado aos 105 alunos que cursaram a disciplina de Cálculo Diferencial e Integral I no primeiro semestre de 2014 com o objetivo de avaliar o conhecimento dos alunos referentes aos conteúdos de Matemática Básica, obter as suas opiniões quanto à disciplina e verificar quais os meios utilizados e o tempo dedicado para os estudos do Cálculo.

Inicialmente, o questionário foi aplicado à turma do terceiro período do curso de Licenciatura em Matemática composto por 18 alunos, dentre os quais alguns eram de outros períodos do curso. Durante a aplicação do questionário, foi possível notar que os alunos tinham dúvidas nos enunciados de duas questões da primeira parte do questionário, sendo elas referentes à interpretação do círculo trigonométrico e a outra abordando a interpretação do domínio e imagem de uma função por meio do gráfico.

Após serem feitas as correções, o questionário foi aplicado à turma do segundo período do curso de Licenciatura em Física, composto por 19 alunos, dos quais alguns eram remanescentes de outros períodos do curso e de outros cursos do campus. 
A terceira turma em que o teste foi aplicado, foi o primeiro período do curso de Bacharelado em Agronomia, composto por 44 alunos, dentre os quais havia alunos remanescentes de outros períodos do curso.

A última turma avaliada foi o primeiro período do curso de Bacharelado em Engenharia Agrícola e Ambiental, composto por 24 alunos, sendo que parte da turma era formada por alunos de outros períodos do curso.

Foi aplicado também outro questionário para os quatro professores que já lecionaram esta mesma disciplina no campus Januária e que ainda estão em atividade neste campus, aqui denominado de Q3, e o último aplicado a 18 alunos da única turma de Cálculo Diferencial e Integral I, aos quais foram oferecidas aulas de monitoria (Q4).

Com referência ao número de aprovações e reprovações, os dados foram obtidos na Secretaria de Registro Acadêmico do campus, por meio dos diários de classe dos professores.

Todos os dados coletados foram contabilizados e analisados minuciosamente, a partir dos quais foi possível responder às questões de pesquisa propostas.

\section{Análise dos dados}

Para efeito de análise são utilizadas as seguintes notações referentes aos cursos: Bacharelado em Engenharia Agrícola e Ambiental (BEAA), Bacharelado em Agronomia (BA), Licenciatura em Matemática (LM) e Licenciatura em Física (LF).

\subsection{Análise do questionário Q1}

Para a análise dos dados foram selecionadas quatro questões da primeira parte do questionário (Q1), por meio das quais serão discutidos erros e dificuldades apresentadas pelos alunos dos cursos superiores.

A primeira questão da primeira parte do questionário a ser analisada (Figura 1), refere-se à equação da reta, em que foi proposto ao aluno encontrar a equação da reta a partir do gráfico dado. 


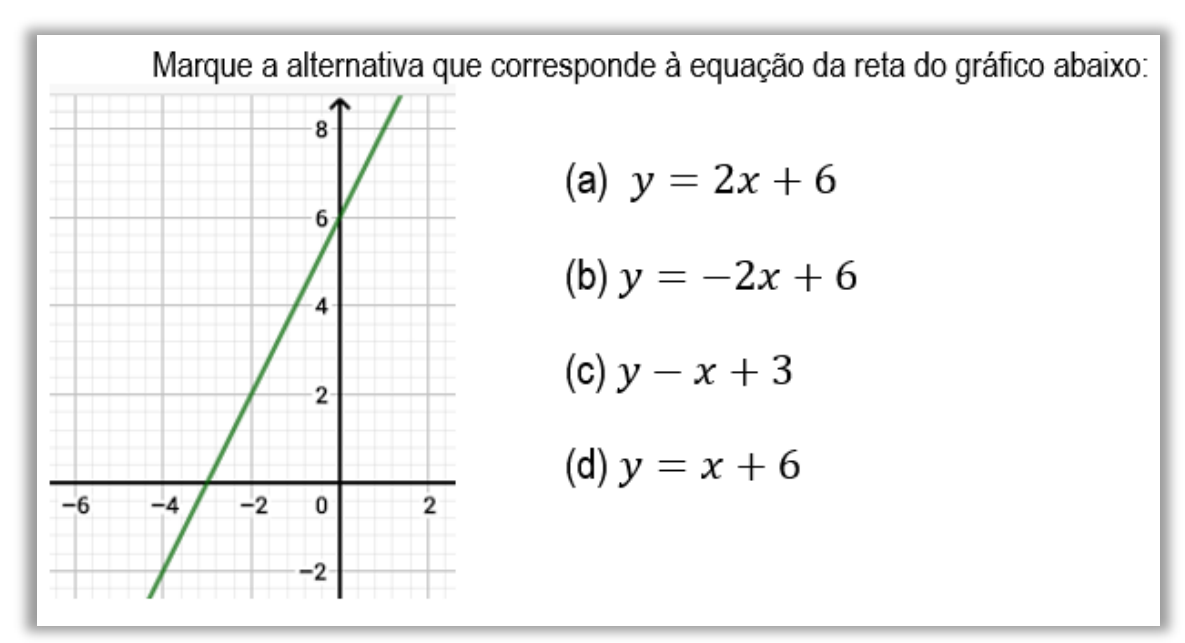

Figura 1: Questão 4 do Teste diagnóstico (Dados da Pesquisa)

Nota-se que na Figura 2(a), o aluno LF resolveu a questão recorrendo ao método de substituição dos valores das coordenadas dos pontos, no entanto confundiu os sinais, o que levou ao erro. Este tipo de erro foi observado nesta e na resolução de outras questões de vários alunos.

Pela Figura 2(b), nota-se que o aluno LM utilizou outra estratégia, buscou verificar a raiz da função, no entanto esqueceu de escrever igual a zero $(-2 x+6=0)$, isso possivelmente implicou o erro seguinte, pois ao tentar resolver a equação, fazendo a compensação mentalmente, ele esqueceu de adicionar com o oposto de (+6) que é $(-6)$ nos dois membros da equação $(-2 x+$ $6+(-6)=0+(-6) \Rightarrow-2 x=-6 \Rightarrow x=3)$, levando ao erro.

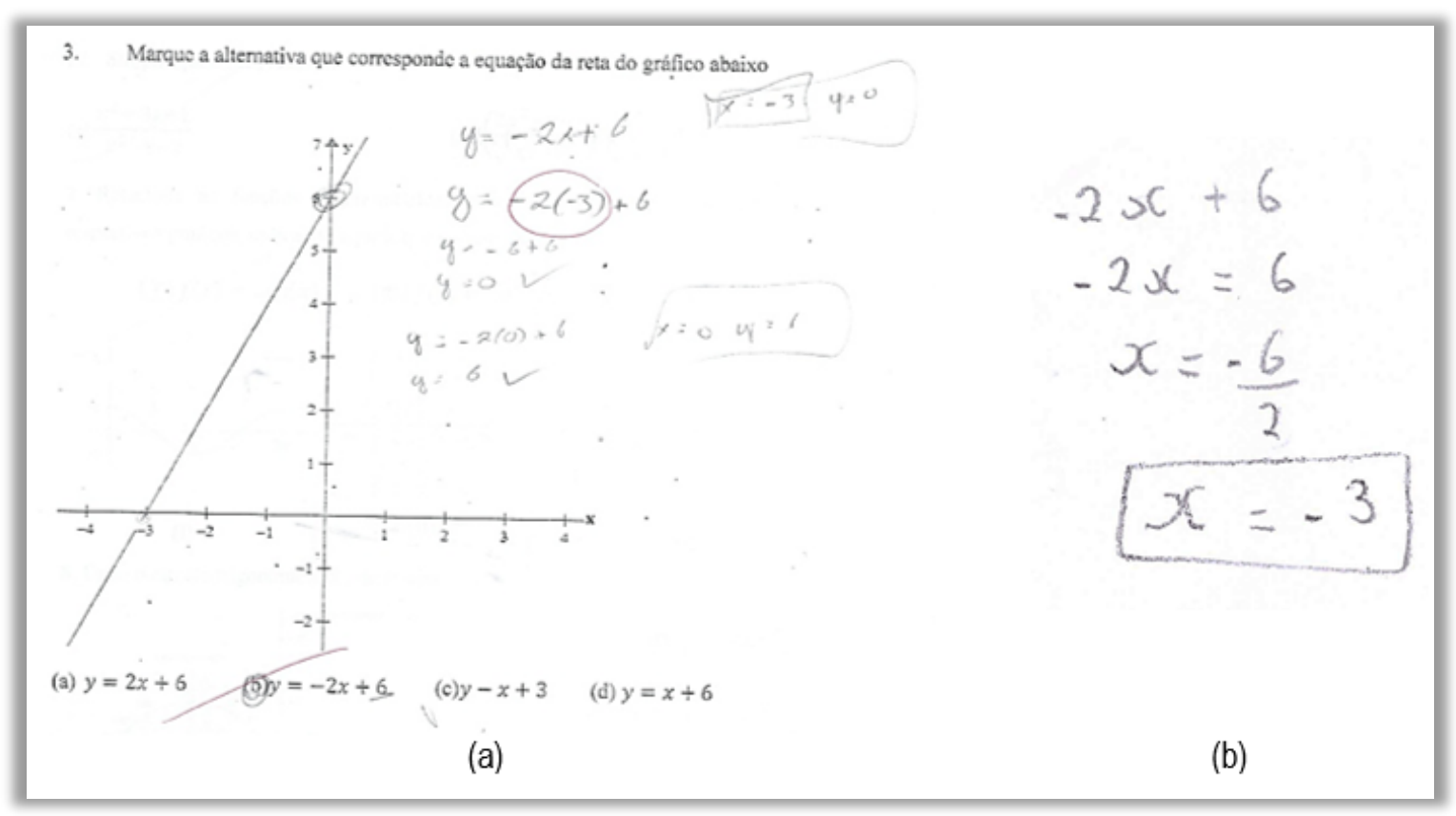

Figura 2: Resolução realizada por um aluno de LF (a) e por aluno de LM (b) (Dados da Pesquisa) 
Pelo Gráfico 1 observa-se o índice percentual de alunos que acertaram, erraram ou não fizeram esta questão.

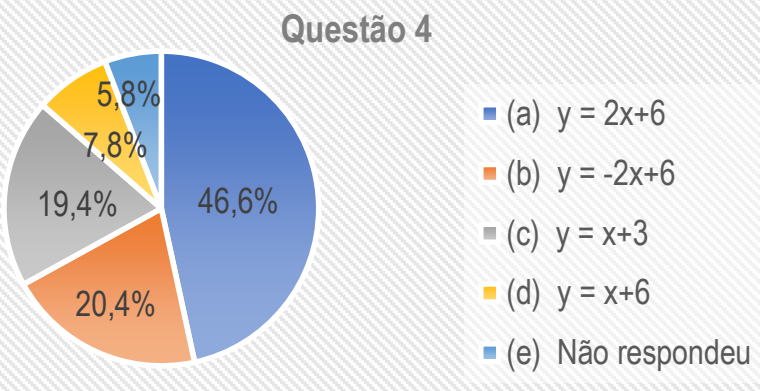

Gráfico 1: Alternativas e suas porcentagens de escolha (Elaboração dos Autores)

Observa-se que $46,6 \%$ dos alunos acertaram a equação da reta, no entanto $47,6 \%$ erraram, marcando outras alternativas, os demais alunos, 5,8\%, simplesmente deixaram de resolver. Outro fato é que $19,4 \%$ dos alunos erraram o sinal da equação, inferindo na conclusão de que uma parcela deles se confunde na manipulação de sinais e muitas vezes não prestam atenção aos cálculos realizados.

A segunda questão do Q1 analisada abordou a resolução de uma equação do segundo grau, em que o objetivo era o cálculo das raízes. A Figura 3 mostra a resolução de um aluno do curso de Bacharelado em Engenharia Agrícola e Ambiental (BEAA).

Observa-se que o aluno tem domínio do tema, porém cometeu um erro comum ao manipular o sinal. 0 aluno se esqueceu do sinal negativo na segunda raiz da equação. 0 erro mais frequente encontrado nas resoluções desta questão foi exatamente no cálculo do sinal na segunda raiz.

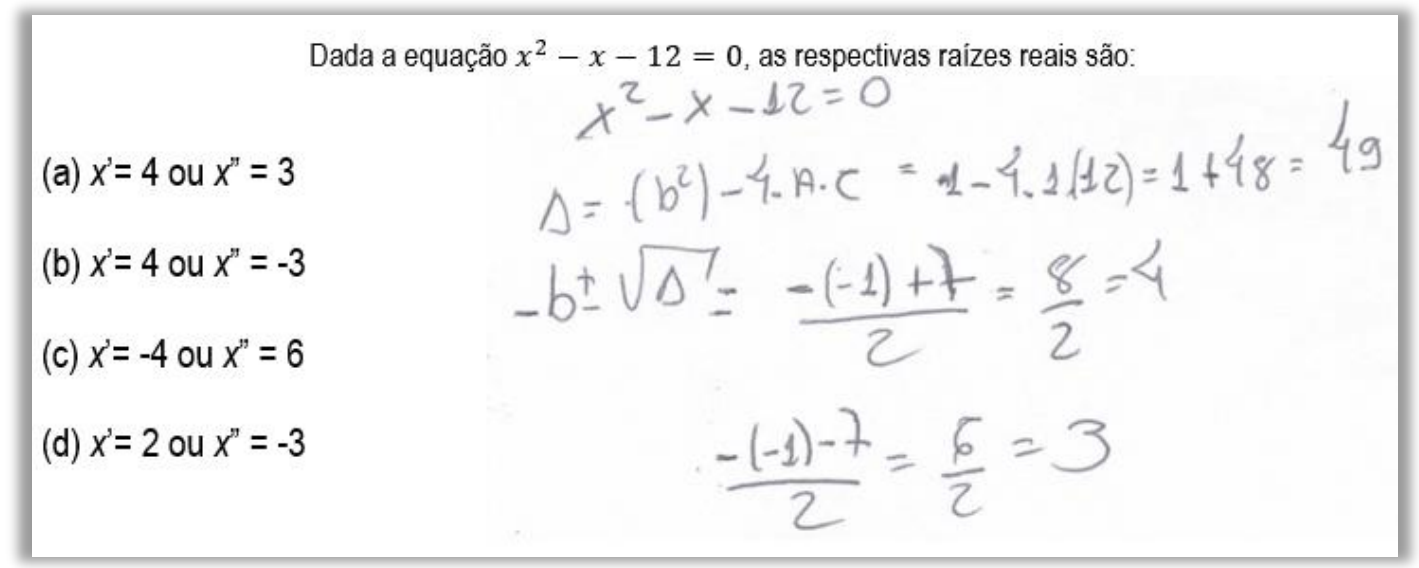

Figura 3: Resolução do aluno BAAE1 (Dados da Pesquisa) 
No Gráfico 2 é possível observar a porcentagem de escolhas das alternativas apresentadas na referida questão. Nota-se que a maioria dos alunos acertou as raízes, $72,4 \%$, e apenas $22,8 \%$ deles marcaram as outras alternativas, sendo que $15,2 \%$ dos alunos erraram no sinal da segunda raiz.

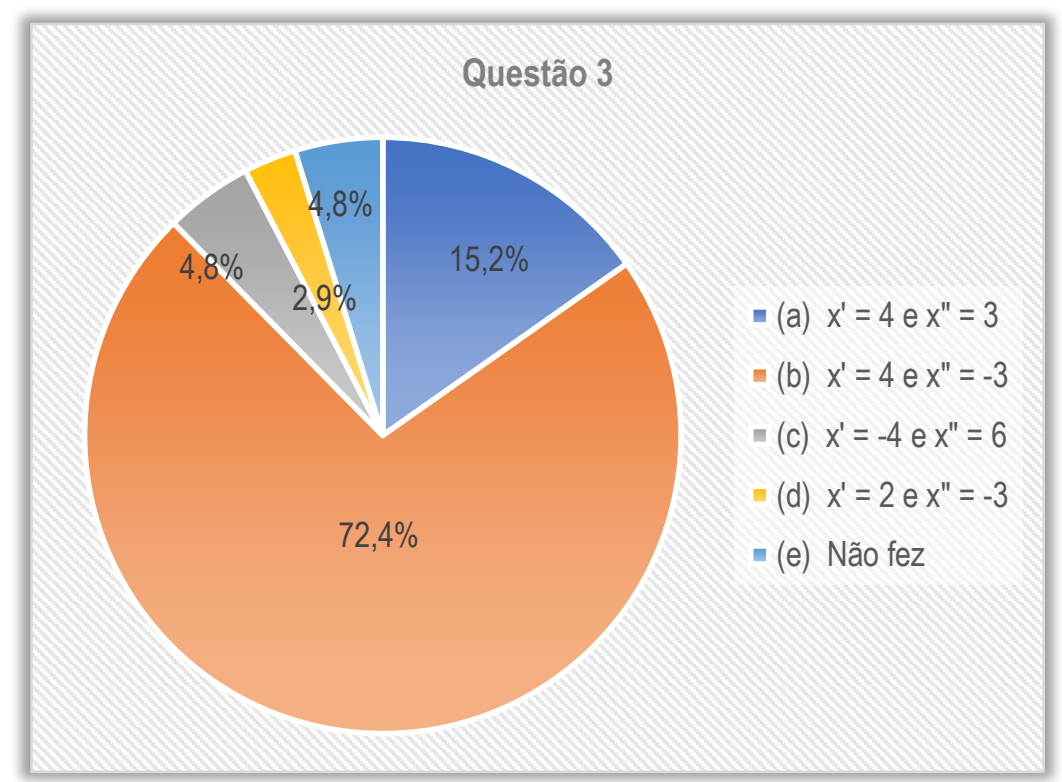

Gráfico 2: Respostas dos alunos em relação à terceira questão do Q1 (Elaboração dos Autores)

Fundamentada na Álgebra, a terceira questão a ser analisa foi elaborada com o objetivo de avaliar o conhecimento dos alunos quanto à simplificação ou fatoração de polinômios.

A Figura 4 mostra esta questão resolvida pelo acadêmico BEAA1 do curso de Bacharelado em Engenharia Agrícola e Ambiental. Nota-se que o aluno tem domínio do conteúdo, pois resolveu corretamente ambas as expressões algébricas.

Simplifique as expressões:
(a) $\frac{x^{2}+3 x+2}{x^{2}-x-2}$
(b) $\left(\frac{2 x^{2}-x-1}{x^{2}-9}\right)\left(\frac{x+3}{2 x+1}\right)$
6. Simplifique as expressões.

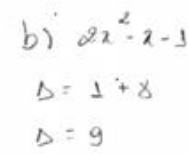

Figura 4: Resolução do aluno BEAA1 (Dados da Pesquisa) 
A mesma questão resolvida pelo aluno BA1 do curso de Bacharelado em Agronomia é mostrada na Figura 5.

6. Simplifique as expressões.

$$
\text { (a) } \frac{x^{2}+3 x+2}{x^{2}-x-2} \quad \frac{3 x+2}{x-2}=\frac{5 x}{2 x}=\frac{5}{2} \text { (b) }\left(\frac{2 x^{2}-x-1}{x^{2}-9}\right)\left(\frac{x+3}{2 x+1}\right) \frac{x}{-9} \cdot \frac{3 x}{3 x}=\frac{x}{-9}
$$

Figura 5: Resolução do aluno BA1 (Dados da Pesquisa)

O aluno cometeu diversos erros algébricos, a começar por simplificar os termos elevado ao quadrado; adicionou números reais com incógnitas, obtendo como resultado um quociente.

No Gráfico 3 pode-se ver os dados desta questão relativos aos acertos, erros e quantidade de alunos que não responderam esta questão aplicada no primeiro questionário. Para o primeiro item desta questão (a), nota-se que do total de 105 alunos avaliados, 54,3\% erraram, 38,1\% não fizeram, e apenas $7,6 \%$ acertaram. Já no segundo item desta questão (b), percebe-se que do total de alunos avaliados, $47,6 \%$ erraram, 46,7\% não fizeram, e apenas 5,7\% acertaram o item. Grande parte dos alunos não conseguiu resolver os itens (a) e (b) dessa questão. Pode-se inferir a partir destes fatos a insegurança dos alunos em pelo menos tentar resolver a questão.

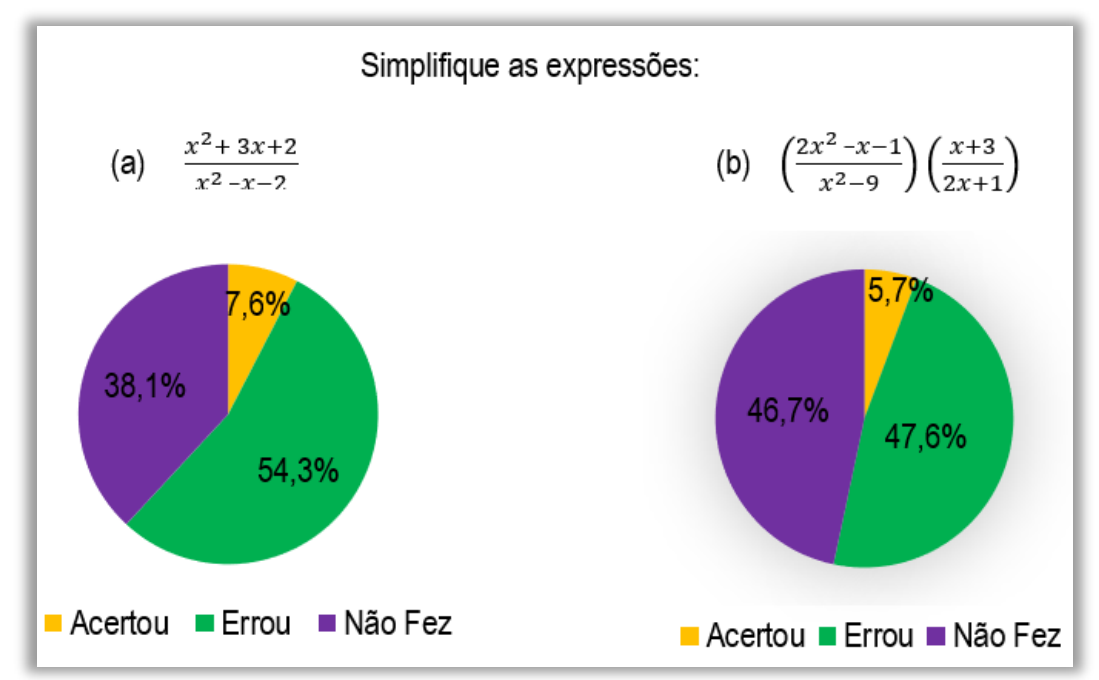

Gráfico 3: Percentual de erros e acertos da sexta questão (Elaboração dos Autores)

A Figura 6 trata da mesma questão resolvida pelo aluno BA2 do curso de Bacharelado em Agronomia, no qual se pode observar que ele tentou resolver a questão a partir dos conhecimentos que possui, e cometeu alguns erros algébricos graves: simplificações impossíveis e adições não existentes. 
obs: Mesta parte possuo u máximo de dificuldade que se possa imaginar...

6. Simplifique as expressões.

(a) $\frac{x^{2}+3 x+2}{x^{2}-x-2}=x^{2}-3 x$

$$
\text { (b) }\left(\frac{2 x^{2}-x-1}{x^{2}-9}\right)\left(\frac{x+3}{2 x+1}\right)=\left(\frac{2-x-1}{-9}\right)\left(\frac{x+3}{2 x+1}\right) \Rightarrow-3-x-1
$$

Figura 6: Resolução do aluno BA2 (Dados da Pesquisa)

O que chama atenção é a frase que ele escreveu na margem superior da folha: "Obs: Nesta parte possuo o máximo de dificuldade que se possa imaginar...". Esse fato mostra a realidade de muitos alunos, que ingressam no Ensino Superior com muitas dificuldades nos conteúdos de Matemática, o que dificulta o aprendizado das disciplinas da área de exatas e a sua compreensão como sendo uma ferramenta de aplicação no desenvolvimento humano.

A quarta questão a ser analisada neste trabalho foi elaborada com o objetivo de avaliar 0 conhecimento dos alunos quanto a obter o valor numérico de uma função e consequentemente verificar se os eles sabiam resolver as operações simples de adição e subtração envolvendo números racionais. A Figura 7 ilustra a resolução desta questão pelo aluno do curso de Bacharelado em Agronomia (BA1).

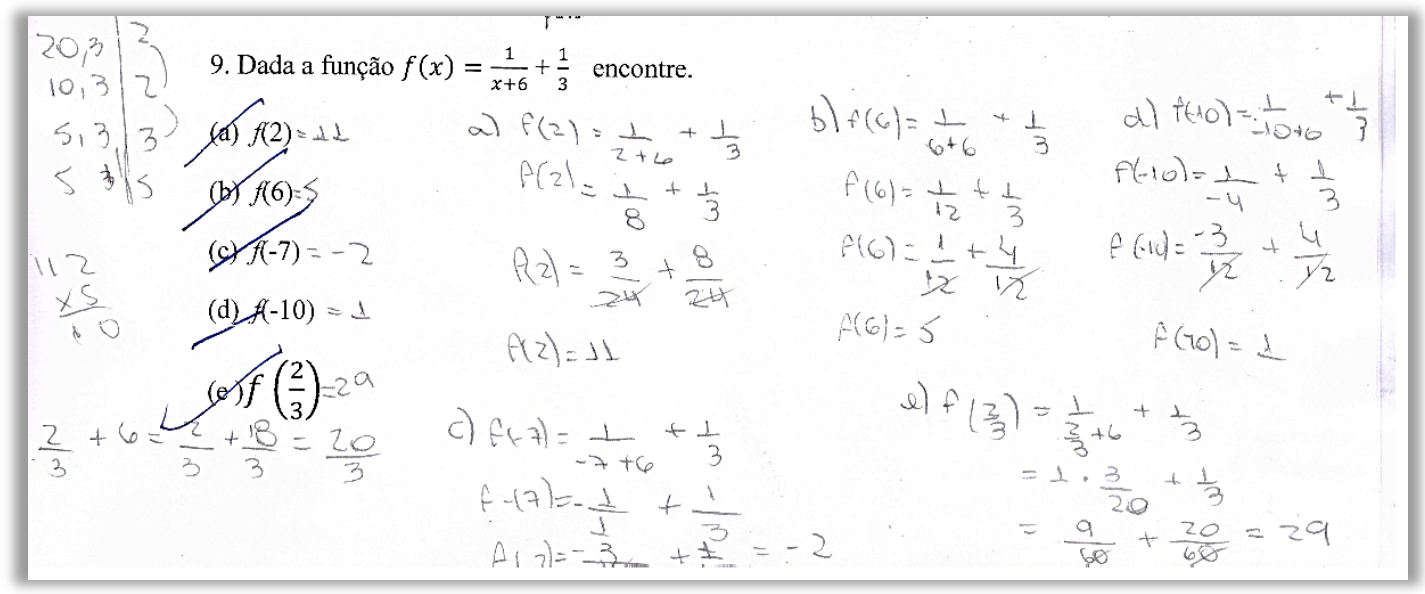

Figura 7: Resolução da nona questão do Q1 pelo aluno BA1 (Dados da Pesquisa)

Nota-se que o aluno realizou a operação do Mínimo Múltiplo Comum (MMC) corretamente, no entanto se confundiu ao simplificar os denominadores após realizar a operação anteriormente citada. Outro erro, este muito comum observado na resolução de outros alunos, corresponde à adição de frações, em que os alunos adicionaram denominador com denominador, numerador com numerador sem antes calcular o MMC entre os denominadores. A Figura 8 ilustra uma dessas resoluções. 
9. Dada a função $f(x)=\frac{1}{x+6}+\frac{1}{3}$ encontre.
(a) $f(2)$
(b) $f(6)$
a) $f(2) \frac{1}{2+6}+\frac{1}{3}=\frac{1}{8}+\frac{1}{3}=\frac{2}{11}$
d) $f(-10)=\frac{1}{20+6}+\frac{2}{3}=\frac{1}{3}$
(c) $f(-7)$
(d) $f(-10)$
(e) $f\left(\frac{2}{3}\right)$
b) $f(6)$ $\frac{1}{6+6}+\frac{1}{3}=\frac{1}{22}+\frac{1}{3}=\frac{2}{15}$
e) $f\left(\frac{2}{3}\right)=\frac{1}{\frac{2}{3}+6}+\frac{1}{3}$
e) $f(-\varphi)=\frac{s}{\varphi+6}+\frac{1}{3}=\frac{2}{16}$

Figura 8: Resolução da nona questão do Q1 pelo aluno LF1 (Dados da Pesquisa)

A resolução desta questão pelo aluno LM1 do curso de Licenciatura em Matemática está na Figura 9. O aluno realizou todas as operações corretamente e mostrou ter domínio de como obter 0 valor numérico de uma função, bem como sobre as operações básicas de adição e subtração com números racionais.

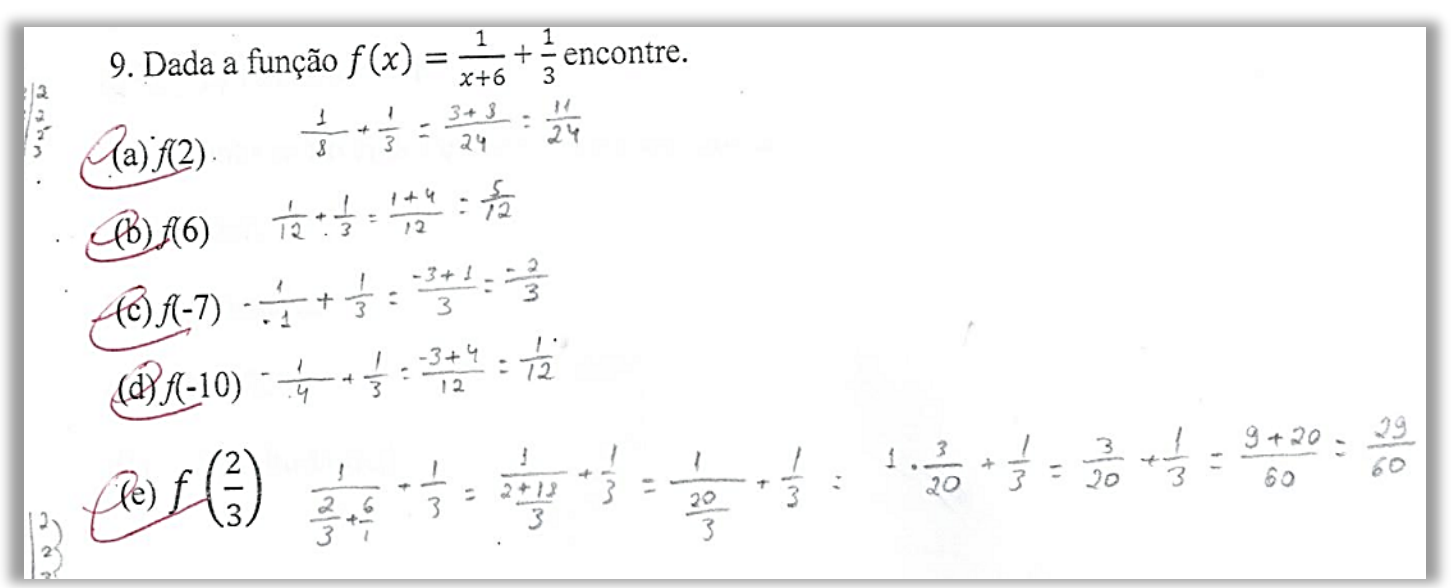

Figura 9: Resolução da questão pelo aluno LM1 (Dados da Pesquisa)

No Gráfico 4 pode se ver os dados relativos à essa questão. Nota-se que a primeira alternativa mostrou ser mais fácil, pois o número de acertos é maior do que o de erros. No entanto, a última alternativa teve menos da metade do número de acertos, o que leva a concluir que, por se tratar de uma fração, os alunos têm mais dificuldades para operar corretamente. 


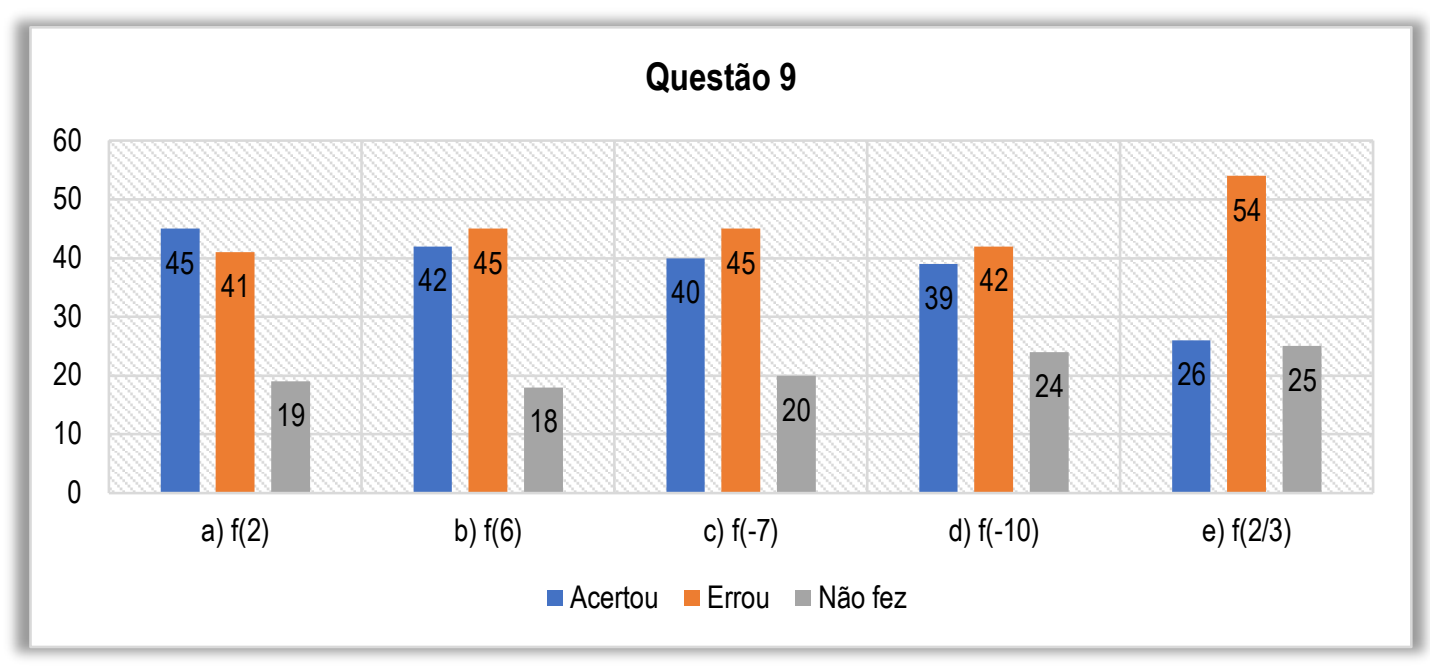

Gráfico 4: Quantidade de erros e acertos da nona questão (Elaboração dos Autores)

\subsection{Análise do questionário Q2}

Foram selecionadas três perguntas da segunda parte do questionário (Q2), que se referem à disciplina de Cálculo Diferencial e Integral I, sendo que a primeira se refere ao tempo dedicado aos estudos da referida disciplina.

A partir do Gráfico 5, pode-se notar que a maioria dos alunos $(69,5 \%)$ dedicam de uma a duas horas por dia para os estudos da disciplina de CDI I, enquanto apenas $8,6 \%$ dedicam mais de três horas diárias. 0 que é preocupante é o fato de que 8,6\% dos alunos responderam não dedicar nenhum tempo para os estudos, o que pode dificultar a aprendizagem dos conteúdos.

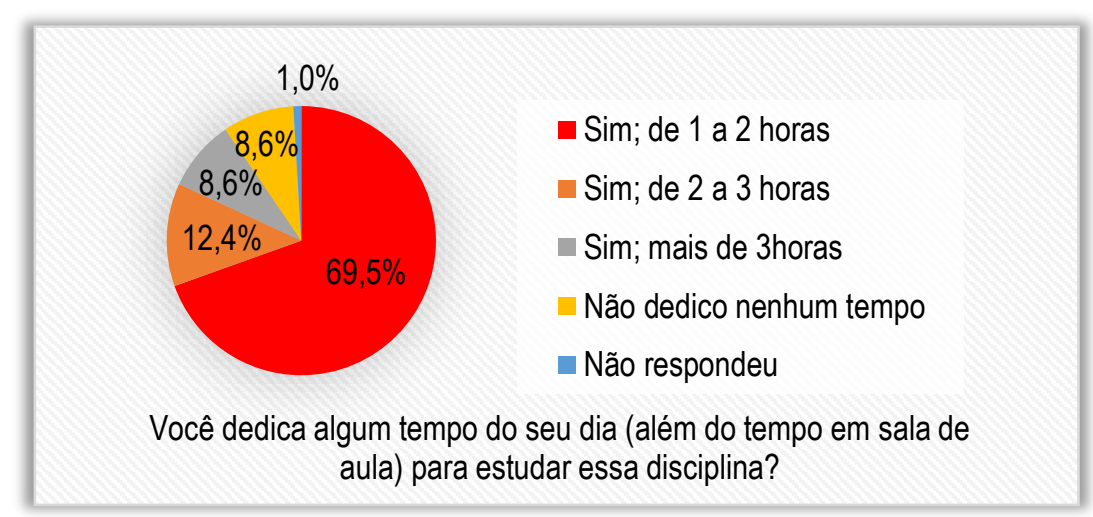

Gráfico 5: Tempo dedicado para os estudos de CDI I (Elaboração dos Autores)

A segunda questão a ser analisada abordou o nível de dificuldade que os alunos possuem em Matemática Básica. O Gráfico 6 mostra o percentual das respostas obtidas. 


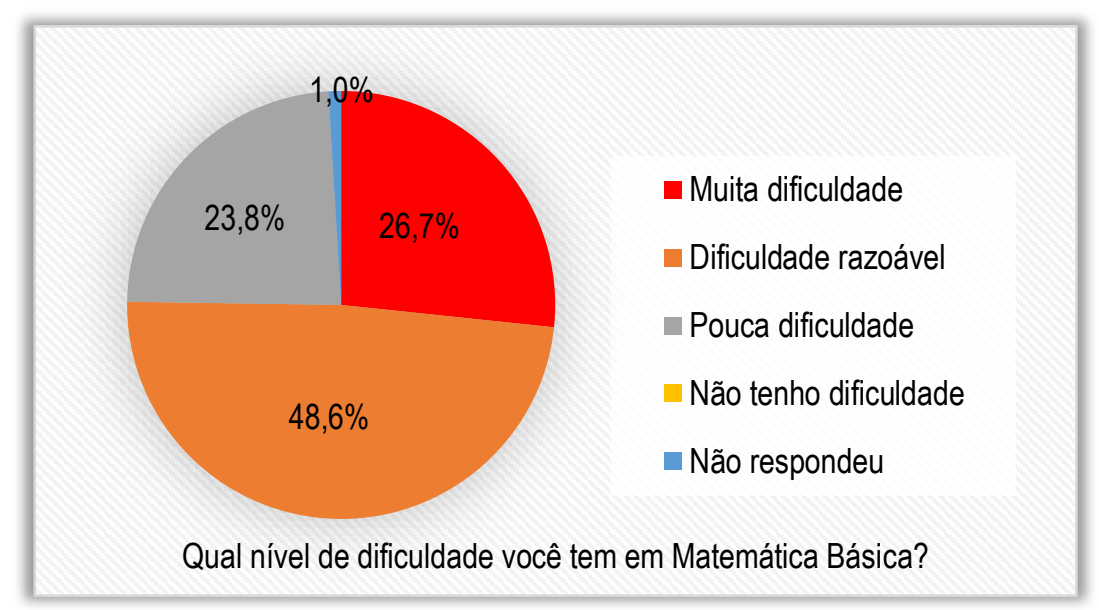

Gráfico 6: Nível de dificuldade em Matemática Básica (Elaboração dos Autores)

Por meio do Gráfico 6, pode-se observar que todos os alunos que responderam à pergunta disseram ter alguma dificuldade nos conteúdos básicos de Matemática, sendo que este nível está variando entre pouca até muita dificuldade.

A terceira questão aborda a compreensão da explicação do professor de CDI I por parte dos alunos, com as opções de 'Sim', 'Não' e 'Às vezes'. O Gráfico 7 corresponde à porcentagem de resposta para cada opção.

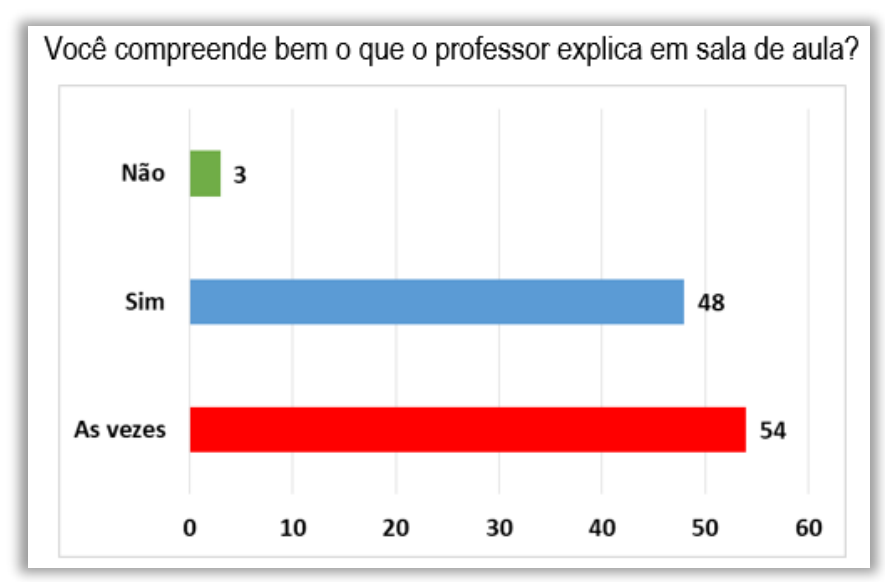

Gráfico 7: Compreensão da explicação do professor (Elaboração dos Autores)

Do total de 105 alunos pesquisados, 54 deles $(51,4 \%)$ disseram que 'Às vezes' entende 0 que o professor explica. Outros 48 alunos (45,7\%) responderam que sim, ou seja, compreende bem as explicações do professor. A partir destas respostas pode-se inferir que os alunos compreendem parcialmente as explicações dos professores, e uma pequena minoria $(2,8 \%)$, responderam não entender nada. 


\subsection{Análise do questionário Q3}

Foram selecionadas três questões do questionário aplicado aos professores. A primeira, refere-se ao maior desafio que o professor enfrenta para lecionar a disciplina de Cálculo Diferencial e Integral I no IFNMG, campus Januária. Nessa questão, os professores podiam marcar mais de uma opção.

Dentre os professores que responderam o questionário, todos marcaram a opção: 'Nível de dificuldade dos alunos'. Este fato mostra que o nível de dificuldade dos alunos em Matemática Básica é um desafio comum entre os professores desta disciplina. Apenas um professor respondeu a opção anterior e 'Falta de interesse dos alunos', o que leva a concluir que este fato não é um desafio que todos os professores enfrentam. As demais opções 'Material didático' e 'Diversificação da aula' não foi indicada por nenhum professor.

Alguns professores citaram outros desafios, como por exemplo: turmas com elevado número de alunos e as dificuldades de explicar de forma dinâmica os conceitos complexos da disciplina.

A segunda questão, Gráfico 8, refere-se às causas de desistências e reprovações na disciplina pesquisada, na qual os professores podiam indicar mais de uma alternativa.

De acordo com os professores do IFNMG, campus Januária, as principais causas de desistências e reprovações no campus são: as dificuldades nos conteúdos de Matemática Básica; a defasagem dos alunos que entram no ensino Superior; e a falta de dedicação dos alunos para com a disciplina.

Quanto às monitorias, os professores foram indagados: Em sua opinião a Monitoria de Cálculo Diferencial e Integral auxilia os alunos na aprendizagem dos conteúdos? Verificou-se que os quatro professores que responderam à questão apoiam as aulas de monitoria como meio de auxiliar os alunos nos estudos da disciplina, como ilustra o Gráfico 8. 
Qual o maior desafio, dentre os citados abaixo, que o professor enfrenta para lecionar Cálculo Diferencial e Integral no IFNMG, campus Januária?

A defasagem dos alunos recém chegados ao ensino Superior

As dificuldades nos conteúdos de Matemática Básica

A metodologia utilizada pelo professor

Falta de dedicação dos alunos para/com a disciplina

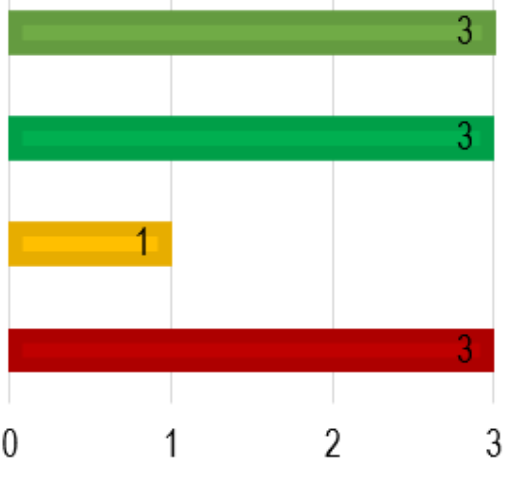

Gráfico 8: Causas de desistências e reprovações (Elaboração dos Autores)

\subsection{Análise do questionário Q4}

O Gráfico 9 refere-se à opinião dos alunos sobre quais os conteúdos eles possuem maiores dificuldades.

De acordo com os alunos que participaram da monitoria, os conteúdos que eles possuem mais dificuldades, em sua maioria é no esboço de gráficos, seguido de integral; o conteúdo de limite vem em terceiro lugar e a derivada por último.

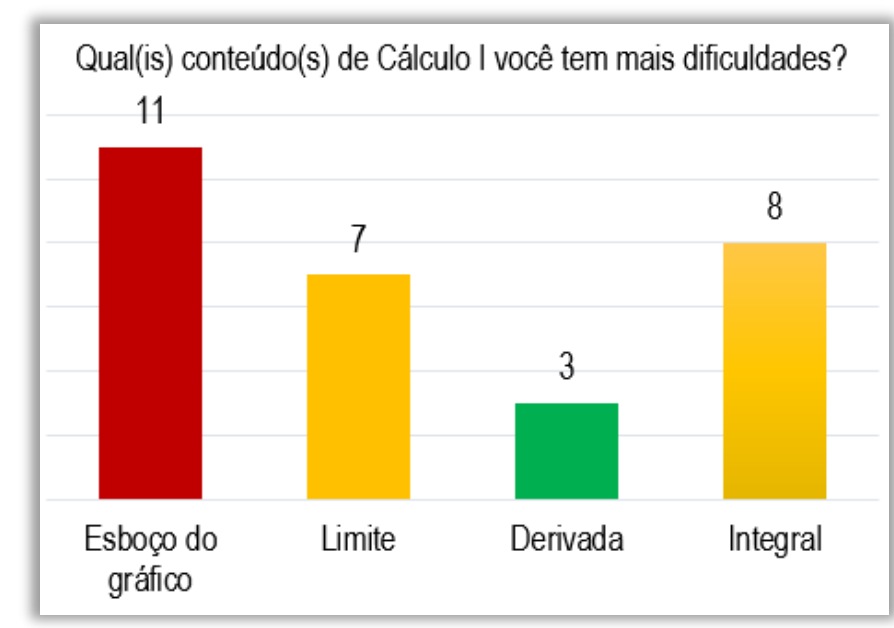

Gráfico 9: Principais dificuldades dos alunos (Elaboração dos Autores)

O Gráfico 10 apresenta um fato importante: a opinião dos alunos acerca da eficiência das aulas de Monitoria. 


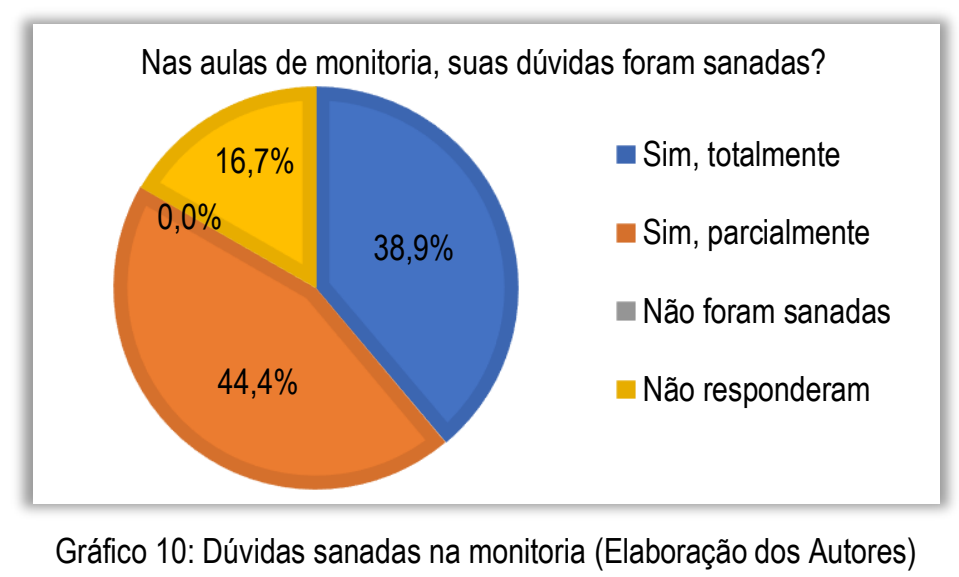

Segundo a opinião dos alunos que compareceram às aulas de monitoria, suas dúvidas foram sanadas totalmente ou parcialmente, em sua maioria $(44,4 \%)$.

\subsection{Análise das aprovações e reprovações na disciplina de Cálculo Diferencial e Integral}

Foram analisados os diários de classes dos professores e contabilizados o número de aprovados, reprovados por nota e por falta em um período de cinco anos. O Gráfico 11 mostra esses números no primeiro semestre de cada ano (a disciplina não foi ministrada no $1^{\circ}$ semestre de 2009).

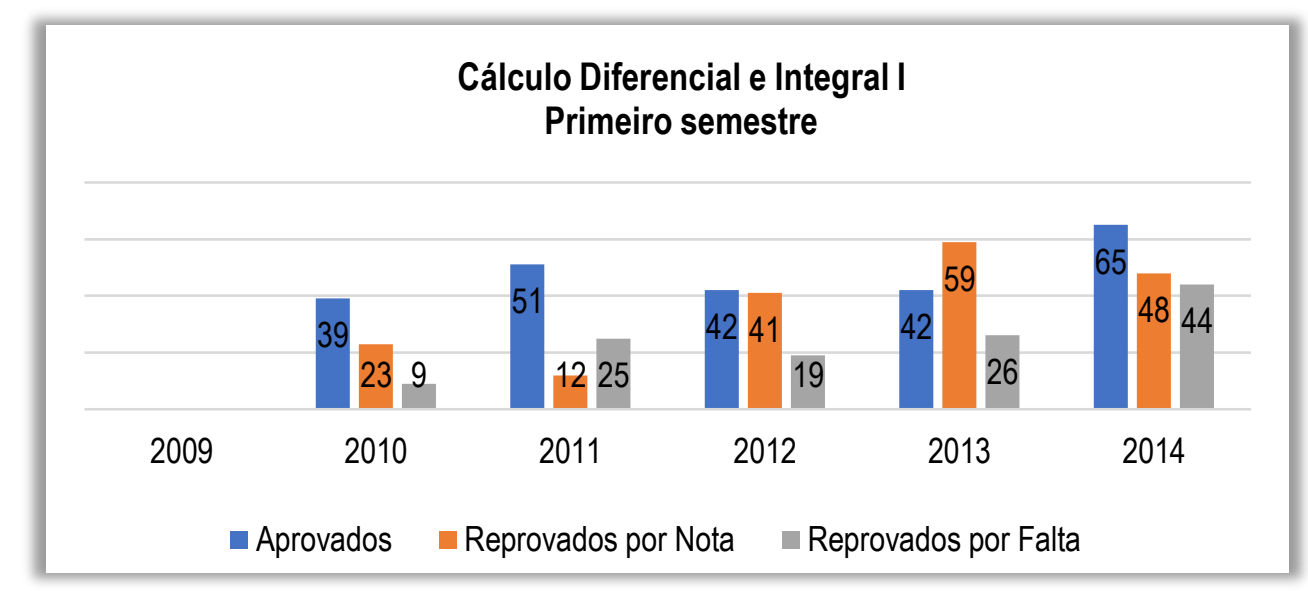

Gráfico 11: Aprovados e Reprovados no $1^{\circ}$ semestre (Elaboração dos Autores)

Observando os dados do Gráfico 11, nota-se que o número de reprovados por falta (alunos com frequência às aulas abaixo de $75,0 \%$ e com notas insuficientes para a aprovação na disciplina) é grande, no ano de 2011 superou o número de reprovados por nota, o que é um fato preocupante. No ano de 2012, o número de reprovados por nota (41) ficou muito próximo do número de aprovados (42). Outro fato preocupante foi no ano de 2013 quando o número de 
reprovados por nota foi superior o número de aprovados, com dezessete alunos a mais.

O Gráfico 12 mostra o número de aprovados, reprovados por falta e por nota referentes ao segundo semestre de cada ano, entre 2009 e 2014 (a pesquisa não possui os dados referentes ao $2^{\circ}$ semestre de 2014). Ele mostra uma realidade que assusta: em todos os anos de 2009 até 2013, exceto em 2011, o número de reprovados por nota foi superior ao número de aprovados, dentre os quais a maior diferença está no ano de 2013, em que a diferença chegou a vinte alunos.

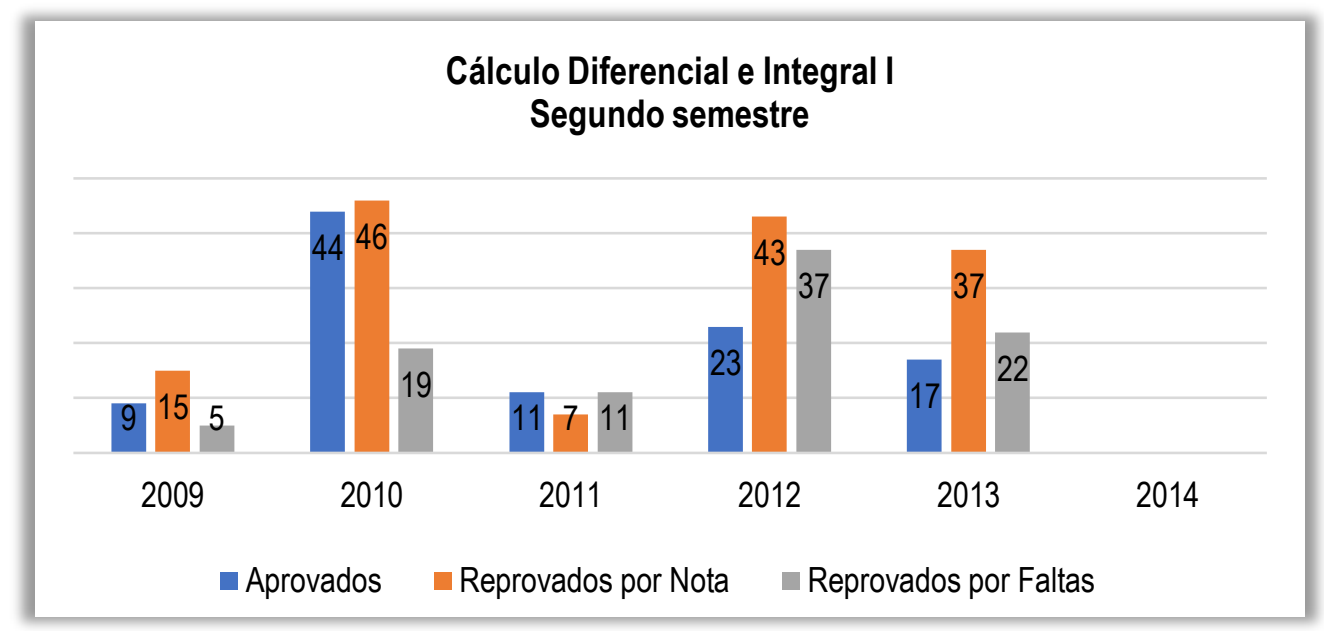

Gráfico 12: Aprovados e Reprovados no $2^{\circ}$ semestre (Elaboração dos Autores)

\section{Considerações}

Por meio desse estudo foi possível observar as principais dificuldades apresentadas pelos alunos dos cursos superiores do IFNMG, campus Januária, nos conteúdos de Matemática Básica necessários para uma melhor aprendizagem e compreensão dos conteúdos do Cálculo Diferencial e Integral, são: manipulação algébricas com polinômios; operações com números racionais e inteiros; interpretação e utilização das regras e propriedades matemáticas; e análise e interpretação de gráficos e operações com os sinais.

De uma forma geral, os alunos apresentam dificuldades nos conteúdos de Matemática Básica, mostrando a realidade do ensino público atual.

A maioria dos alunos dedicam de uma a duas horas diárias apenas para os estudos da disciplina de CDI I, o que dificulta o aprendizado. Mais da metade dos alunos que responderam o teste, disseram não entender todas as explicações dos professores.

Contudo, mostra-se necessária uma intervenção dinâmica e objetiva para melhorar a 
aprendizagem dos alunos na disciplina de CDI I, pois, sendo esta parte importante do desenvolvimento do conhecimento, se torna importante também a sua compreensão e aprendizagem.

Após a análise dos dados, observa-se que os alunos chegam ao IFNMG, campus Januária, com dificuldades nos conteúdos básicos de Matemática, mostrando a defasagem do ensino público; também não conseguem compreender por completo as explicações dos professores.

Os professores que atuam no campus Januária conhecem as dificuldades dos alunos, e as causas de tantas reprovações por notas e por faltas e buscam ajudar de alguma forma. Uma delas é o apoio total nas aulas de monitoria, que segundo a opinião docente e, também, discente, auxiliam os alunos nos conteúdos da disciplina.

Os alunos que participaram das aulas de monitoria apresentaram suas dúvidas e dificuldades, sendo que a maioria foi considerada como sanada. Foi possível responder a pergunta sobre quais os conteúdos que os alunos tinham mais dificuldades, sendo os principais o esboço de gráficos e o cálculo de integrais.

Quanto ao número de aprovações e reprovações, foi possível verificar que esses dados são preocupantes, sendo necessário um esforço conjunto de toda a comunidade acadêmica para sanar essa questão.

A aversão e as dificuldades dos alunos pelas disciplinas de exatas e principalmente em relação ao CDI, estão intimamente relacionados com a falta dos conhecimentos prévios adquiridos na educação básica, bem como com a forma que os conteúdos estão sendo ensinados no ensino superior.

É importante salientar as medidas que estão sendo tomadas para a melhoria do ensino das disciplinas de CDI, principalmente a adoção das atividades de monitoria, no entanto faz-se necessário repensar as estruturas curriculares, bem como as posturas didáticas e metodológicas.

É certo que muito ainda se tem que fazer para a melhoria nos processos de ensino e aprendizagem do CDI no Ensino Superior. Aperfeiçoar o modo de ensinar e criar formas de apoiar os alunos a suprirem suas dificuldades são alguns dos possíveis caminhos. 


\section{Referências}

BRESSAN, Philippe Messias; AZAMBUJA, Cármen; GONÇALVES, Neda; MULLER, Marilene Jacintho. Cálculo diferencial e integral I: investigação sobre dificuldades dos alunos. In: X SALÃO DE INICIAÇÃO CIENTíFICA PUCRS, 2009, Porto Alegre. Anais do X Salão de Iniciação Científica PUCRS. Porto Alegre: PUCRS, 2009. p. 1172-1175.

CAVASSOTTO, Marcelo; PORTANOVA, Ruth. Reflexões sobre as dificuldades na aprendizagem de Cálculo Diferencial e Integral. In: III MOSTRA DE PESQUISA DA PÓS GRADUAÇÃO PUCRS, 2008, Porto Alegre. Anais da III Mostra de Pesquisa da Pós-Graduação PUCRS. Porto Alegre: PUCRS, 2008, p. 1-6.

FREIRE, Paulo. Pedagogia da autonomia: saberes necessários à prática educativa. 43. ed. São Paulo: Paz e Terra, 2011.

GODOY, Luiz Felipe Simões de; FARIA, Wellington Cássio. O cálculo diferencial e integral e suas aplicações no ensino de Engenharia: uma análise de currículo. In: CONGRESSO DE INICIAÇÃO CIENTÍFICA DO INATEL, 2012, Santa Rita do Sapucaí. Anais do INCITEL 2012. Santa Rita do Sapucaí: INATEL, 2012. p. 125-132.

GOMES, Eloiza. Ensino e aprendizagem de cálculo na engenharia: um mapeamento das publicações nos COBENGEs. In: XVI ENCONTRO BRASILEIRO DE ESTUDANTES DE PÓS GRADUAÇÃO EM EDUCAÇÃO MATEMÁTICA, 2012, Canoas. Anais do XVI EBRAPEM. Canoas: ULBRA, 2012, p. 1-9.

GREGOR, Isabela Cristina Soares; MACÊDO, Josué Antunes de. Reflexões sobre o ensino e aprendizagem de cálculo diferencial e integral no Instituto Federal do Norte de Minas Gerais. In: IV SIMPÓSIO INTERNACIONAL DE PESQUISA EM EDUCAÇÃO MATEMÁTICA, 2015, Ihéus. Anais do IV SIPEMAT: Educação Matemática e contextos da diversidade cultural. Ilhéus: UESC, 2015, p. 875-886.

GREGOR, Isabela Cristina Soares; MACÊDO, Josué Antunes de; AMORIM, Lílian Isabel Ferreira. Dificuldades apresentadas por alunos da disciplina de Cálculo Diferencial e Integral I no IFNMG analisadas em um teste de Matemática básica. In: V ENCONTRO NACIONAL DAS LICENCIATURAS, 2014, Natal. Anais do V ENALIC. Natal: UFRN, 2014, p. 1-12.

GREGOR, Isabela Cristina Soares; ROCHA, Jesiane Rodrigues da; MACÊDO, Josué Antunes de; BORBA JUNIOR, Waldomiro Rodrigues. Dificuldades de ensino e aprendizagem de Cálculo Diferencial e Integral no IFNMG e o uso de softwares matemáticos. In: IV SEMINÁRIO NACIONAL DE EDUCAÇÃO PROFISSIONAL E TECNOLÓGICA, 2014, Belo Horizonte. Anais do IV SENEPT. Belo Horizonte: CEFETMG, 2014, p. 1-15.

GUEDIN, Juliana. Cálculo diferencial e integral: o ensino como uma abordagem histórica e suas contextualizações. 2004. 46f. Monografia (Especialização em Educação Matemática) Universidade do Extremo Sul Catarinense. Criciúma.

LACAZ, Tânia Maria Vilela Salgado; CARVALHO, Maria Tereza Lima; FERNANDES, José António Silva. Implicações das dificuldades dos alunos na aprendizagem da disciplina cálculo diferencial e integral I da FEG/UNESP para as práticas pedagógicas. In: XXXV CONGRESSO BRASILEIRO 
DE EDUCAÇÃO EM ENGENHARIA, 2007, Curitiba. Anais do XXXV COBENGE: Novos paradigmas da Educação em Engenharia. Curitiba: ABENGE, 2007, p. 1-12.

MACÊDO, Josué Antunes de; SANTOS, Acárem Chrísler Ferreira dos. Estudo de funções transcendentes usando o software GeoGebra. Revista de Educação, Ciências e Matemática, Duque de Caxias, v. 9, n. 1, jan./abr. 2019.

NASSER, Lilian. Ajudando a superar obstáculos na aprendizagem de cálculo. In: IX ENCONTRO NACIONAL DE EDUCAÇÃO MATEMÁTICA, 2007, Belo Horizonte. Anais do IX ENEM. Belo Horizonte: SBEM, 2007, p. 1-13.

REZENDE, Wanderley Moura. O ensino de Cálculo: dificuldades de natureza epistemológica. In: MACHADO, Nílson José; CUNHA, Marisa Ortegosa da. (Org.). Linguagem, Conhecimento, Ação: ensaios de epistemologia e didática. São Paulo: Escrituras, 2003, p. 313-336.

RODRIGUES, Márcio Gomes; MOURA, Kelly Cristine Rodrigues de; MOURA, Márcio Cleto Soares de; MENDES, Wanderson de Sousa; NASCIMENTO, Robson de Souza. Cálculo diferencial e integral: analisando e refletindo os fatores que interferem no desempenho acadêmico da disciplina, no CPE/UFPI. In: XX SEMINÁRIO DE INICIAÇÃO CIENTíFICA, 2011, Teresina. Resumos do XX Seminário de Iniciação Científica. Teresina: UFPI, 2011.

SANTOS, Acárem Chrísler Ferreira dos; MACÊDO, Josué Antunes de. A utilização das tecnologias digitais na formação inicial de professores de matemática e física. In: XI ENCONTRO NACIONAL DE EDUCAÇÃO MATEMÁTICA, 2013, Curitiba. Anais do XI ENEM: Educação Matemática: Retrospectiva e Perspectivas. Curitiba: SBEM, 2013, p. 1-16.

SANTOS, Acárem Chrísler Ferreira dos; MACÊDO, Josué Antunes de. Uso dos softwares geogebra e winplot no estudo de funções transcendentes. Revista Eletrônica de Educação Matemática, Florianópolis, v. 10, n. 2, p. 155-166, dez. 2015.

SANTOS, Marcéu Veríssimo Ramos dos; CARNEIRO, Isabel Magda Said Pierre. Dificuldades de aprendizagem no ensino do cálculo diferencial e integral I: implicações para o trabalho docente. In: XXI ENCONTRO DE PESQUISA EDUCACIONAL DO NORTE E NORDESTE, 2013, Recife. Anais do XXI EPENN: Internacionalização da educação e desenvolvimento regional. Recife: UFPE, 2013, p. 1-16.

SILVA, Benedito Antonio da. Componentes do processo de ensino e aprendizagem do cálculo: saber, aluno e professor. In: IV SEMINÁRIO INTERNACIONAL DE PESQUISA EM EDUCAÇÃO MATEMÁTICA, 2009, Brasília. Caderno de Resumos do IV SIPEM. Brasília: SBEM, 2009, p. 123124.

VIEIRA, Aldo Freitas. Ensino de cálculo diferencial e integral das técnicas ao humans-whit-media. 2013. 204f. Tese (Doutorado em Educação) — Faculdade de Educação. Universidade de São Paulo. São Paulo.

WROBEL, Julia Schaetzle; ZEFERINO, Marcus Vinicius Casoto; CARNEIRO, Teresa Cristina Janes. Um mapa do ensino de Cálculo nos últimos 10 anos do COMBENGE. In: XLI CONGRESSO BRASILEIRO DE EDUCAÇÃO EM ENGENHARIA, 2013, Gramado. Anais do XLI COMBENGE: Educação na era do conhecimento. Gramado: ABENGE, 2013, p. 1-12. 